\title{
First detection and report of SARS-CoV-2 Spike protein N501Y mutations in Oklahoma USA
}

Sai Narayanan ${ }^{1}$, Girish Patil ${ }^{1}$, Sunil More ${ }^{2}$, Jeremiah Saliki ${ }^{1}$, Anil Kaul ${ }^{3}$, Akhilesh Ramachandran ${ }^{1}$

${ }^{1}$ Oklahoma Animal Disease Diagnostic Laboratory, College of Veterinary Medicine, Oklahoma State University, Stillwater OK 74078

${ }^{2}$ Department of Veterinary Pathobiology, College of Veterinary Medicine, Oklahoma State University, Stillwater, OK 74078

${ }^{3}$ Center for Health Sciences, Oklahoma State University, Tulsa, OK 74107 
medRxiv preprint doi: https://doi.org/10.1101/2021.01.26.21250584; this version posted January 29, 2021. The copyright holder for this preprint

(which was not certified by peer review) is the author/funder, who has granted medRxiv a license to display the preprint in perpetuity.

It is made available under a CC-BY-NC-ND 4.0 International license.

\begin{abstract}
:
We describe the detection of SARS-CoV-2 (VOC )B.1.1.7 lineage in Oklahoma, USA. Various mutations in the S gene and ORF8 with similarity to the genome of B.1.1.7 lineage were detected in 4 of the 6 genomes sequenced and reported here. The sequences have been made available in GISAID. Presence of novel lineages indicate the need for frequent whole genome sequencing to better understand pathogen dynamics in different geographical locations.
\end{abstract}

Keywords: SARS-CoV-2, B.1.1.7, Variant of Concern (VOC), mutations, Oklahoma (USA) 
Since the start of the COVID-19 pandemic in December 2019, several lineages/variants of SARS-CoV-2 have been identified based on whole genome sequencing. As of January 21, 2021 approximately 420,000 whole genome sequences have been deposited in the GISAID database (https://www.gisaid.org/) (1,2). Recently a novel SARS-CoV-2 lineage (B 1.1.7.) was identified in Kent and Greater London in the United Kingdom (3) and is reported to have enhanced transmissibility. Infections by the B.1.1.7 lineage has since been reported from several other countries including the United States (4). We report the identification of B.1.1.7 in Oklahoma, USA.

COVID-19 was first reported in Oklahoma on March $6^{\text {th }} 2020$ (5). As of January $19^{\text {th, }} 2021$, a total of 358,374 cases and 3,037 deaths have been registered in the state (6). Six clinical samples, from different counties in the state, collected between January $1^{\text {st }}$ and $8^{\text {th }}, 2021$, were sequenced for this report. RNA was extracted using a commercial kit (MVP, ThermoFisher) and viral presence was detected by real-time PCR using TaqPath COVID-19 kit (Thermofisher, MA, USA) that targets the $\mathrm{S}$ gene, $\mathrm{N}$ gene and ORF $1 \mathrm{ab}$. The $\mathrm{S}$ gene target of all the samples selected for sequencing either failed to amplify or had $\mathrm{Ct}$ values that were higher when compared to $\mathrm{N}$ gene and ORF1ab. Sequencing was performed using the MinION platform (Oxford Nanopore Technologies, UK ) following the ARTIC protocol (7).

Sequenced genomes were assembled using canu (8). Reference assisted consensus assemblies were generated using minimap2 (9) and nanopolish (10), SARS-CoV-2 reference genome Wuhan-Hu-1 (GenBank ID: MN908947.3) was used for reference assembly. Individual genes were annotated using VIGOR (11). Annotated genes and the whole genomes were aligned using MUSCLE aligner in MEGA-X (12). The genome sequences were submitted to GISAID (1) and their GISAID classification and PANGO lineages (13) are shown in table 1. Four of the six samples sequenced carried SNPs similar to those described in the B.1.1.7 lineage (20I/501 Y.V1 Variant of Concern (VOC) 202012/01) (4), including N501Y, 69/70 deletion, Y144 deletion, A570D, P681H, T716I, S982A, D1118H mutations. Q27Stop mutation in ORF 8 was detected in 3 out of these 4 samples. N501Y and the previously described D614G mutations $(14,15)$ were detected in all 6 samples (Table 2).

Frequent whole genome sequencing is critical to monitor mutations in the viral genome. The evolution of highly transmissible strains of SARS-CoV-2 and its global spread underlines the need to remain vigilant and continue practicing necessary social measures to prevent further disease spread. 


\begin{tabular}{|l|l|l|l|l|}
\hline Genome & Coverage & GISAID Accession No. & GISAID Clade & PANGO Lineage \\
\hline Oklahoma-ADDL-6 & $36932.1 \times$ & EPI_ISL_812346 & GR & B.1.1.7 \\
\hline Oklahoma-ADDL-7 & $2080.4 \times$ & EPI_ISL_861422 & G & B.1.1.7 \\
\hline Oklahoma-ADDL-8 & $1963.7 \times$ & EPI_ISL_861423 & GR & B.1.1.7 \\
\hline Oklahoma-ADDL-9 & $2192.3 \times$ & EPI_ISL_861424 & G & B.1.1.7 \\
\hline Oklahoma-ADDL-10 & $3992.5 \times$ & EPI_ISL_861425 & GH & B.1 \\
\hline Oklahoma-ADDL-11 & $4399.6 \times$ & EPI_ISL_861426 & GH & B.1 \\
\hline
\end{tabular}

Table 1: Genome coverage of SARS-CoV-2 sequenced from different samples. GISAID Accession No., Clade and PANGO (Phylogenetic Assignment of Named Global Outbreak) Lineage from GISAID are shown.

\begin{tabular}{|l|l|l|}
\hline \multicolumn{1}{|c|}{$\begin{array}{c}\text { Mutations observed } \\
\text { (Nucleotide position) }\end{array}$} & \multicolumn{1}{c|}{ Gene } & \multicolumn{1}{c|}{ Genomes with mutation } \\
\hline N501Y (A23063T) & S gene & Oklahoma-ADDL-6, 7,8,9,10,11 \\
\hline A570D (C23271A) & S gene & Oklahoma-ADDL-6,7,9 \\
\hline D614G (A23403G) & S gene & Oklahoma-ADDL-6, 7,8,9,10,11 \\
\hline P681H (C23604A) & S gene & Oklahoma-ADDL-6,7,8,9 \\
\hline T716I $(\mathrm{C} 23709 \mathrm{~T})$ & S gene & Oklahoma-ADDL-6,7,8,9 \\
\hline S982A (T24506G) & S gene & Oklahoma-ADDL-6,7,8,9 \\
\hline D1118H (G24914C) & S gene & Oklahoma-ADDL-6 \\
\hline 69/70 (21765 - 21770) DEL & S gene & Oklahoma-ADDL-6,7,8,9 \\
\hline Y144 DEL (21991 - 21993) & S gene & Oklahoma-ADDL-6,7,8,9 \\
\hline Q27Stop (C27972T) & ORF 8 & Oklahoma-ADDL-6,7,8 \\
\hline
\end{tabular}

Table 2: Selected mutations detected in $\mathrm{S}$ gene and ORF 8, and their respective amino acid changes when compared to NCBI reference genome (SARS-CoV-2, Wuhan Hu-1, NC 045512.2).

\section{Ethics Statement:}

This study was approved by the Institutional Review Board (Application number: IRB-20-357) at Oklahoma State University, Stillwater OK 74078, United States.

\section{Acknowledgment}

We thank Dr. Yiwei Wang and Dr. Jeremy Kaplan for their help in sample collection. Study was partially funded by FDA-CVM-VetLIRN (Grant no.5U18FD006671-02). 


\section{References:}

1. Elbe S, Buckland-Merrett G. Data, disease and diplomacy: GISAID's innovative contribution to global health. Glob challenges (Hoboken, NJ) (2017) 1:33-46. doi:10.1002/gch2.1018

2. Mak G. Important note: In the GISAID EpiFlu ${ }^{\mathrm{TM}}$ Database Access Agreement, you have accepted certain terms and conditions for viewing and using data regarding influenza viruses. To the extent the Database contains data relating to non-influenza viruses, the viewing. (2020)413498.

3. Chand, Meera; Hopkins, Susan; Dabrera, Gavin; Achison, Christina; Barclay, Wendy; Ferguson, Neil; Volz, Erik; Loman, Nick; Rambaut, Andrew; Barrett J (21 D 2020). I of novel S-C-2 variant: V of C 202012/01 (PDF) (Report). PHE p. 2. R 22 D 2020. Investigation of novel SARS-COV-2 variant- Variant of Concern 202012/01. (2020). Available at: https://assets.publishing.service.gov.uk/government/uploads/system/uploads/attachment_d ata/file/947048/Technical_Briefing_VOC_SH_NJL2_SH2.pdf

4. Emerging SARS-CoV-2 Variants. (2021) Available at: https://www.cdc.gov/coronavirus/2019-ncov/more/science-and-research/scientific-briefemerging-variants.html

5. First Case of Coronavirus Confirmed in Tulsa County. Available at: https://www.kjrh.com/news/local-news/first-case-of-coronavirus-confirmed-in-tulsacounty

6. OSDH-COVID-19 Tracker. (2020) Available at: https://coronavirus.health.ok.gov/sites/g/files/gmc786/f/2020.07.10_weekly_epi_report.pd $\mathrm{f}$

7. Lu J, du Plessis L, Liu Z, Hill V, Kang M, Lin H, Sun J, François S, Kraemer MUG, Faria NR, et al. Genomic Epidemiology of SARS-CoV-2 in Guangdong Province, China. Cell (2020) 181:997-1003.e9. doi:https://doi.org/10.1016/j.cell.2020.04.023

8. Koren S, Walenz BP, Berlin K, Miller JR, Bergman NH, Phillippy AM. Canu: scalable and accurate long-read assembly via adaptive $\mathrm{k}$-mer weighting and repeat separation. Genome Res (2017) 27:722-736. doi:10.1101/gr.215087.116

9. Li H. Minimap2: pairwise alignment for nucleotide sequences. Bioinformatics (2018) 34:3094-3100. doi:10.1093/bioinformatics/bty191

10. Loman NJ, Quick J, Simpson JT. A complete bacterial genome assembled de novo using only nanopore sequencing data. Nat Methods (2015) 12:733-735. doi:10.1038/nmeth.3444

11. Wang S, Sundaram JP, Stockwell TB. VIGOR extended to annotate genomes for additional 12 different viruses. Nucleic Acids Res (2012) 40:W186-W192. doi:10.1093/nar/gks528 
medRxiv preprint doi: https://doi.org/10.1101/2021.01.26.21250584; this version posted January 29, 2021. The copyright holder for this preprint

(which was not certified by peer review) is the author/funder, who has granted medRxiv a license to display the preprint in perpetuity.

It is made available under a CC-BY-NC-ND 4.0 International license.

12. Kumar S, Stecher G, Li M, Knyaz C, Tamura K. MEGA X: Molecular Evolutionary Genetics Analysis across Computing Platforms. Mol Biol Evol (2018) 35:1547-1549. doi:10.1093/molbev/msy096

13. Rambaut A, Holmes EC, O’Toole Á, Hill V, McCrone JT, Ruis C, du Plessis L, Pybus OG. A dynamic nomenclature proposal for SARS-CoV-2 lineages to assist genomic epidemiology. Nat Microbiol (2020) 5:1403-1407. doi:10.1038/s41564-020-0770-5

14. Narayanan S, Ritchey JC, Patil G, Teluguakula N, More S, Malayer J, Saliki J, Kaul A, Ramachandran A. SARS-CoV-2 genomes from Oklahoma, USA. medRxiv (2020)2020.09.15.20195420. doi:10.1101/2020.09.15.20195420

15. Daniloski Z, Guo X, Sanjana NE. The D614G mutation in SARS-CoV-2 Spike increases transduction of multiple human cell types. bioRxiv (2020)2020.06.14.151357. doi:10.1101/2020.06.14.151357 